\title{
Ménétrier's disease presenting as recurrent unprovoked venous thrombosis: a case report
}

\author{
H. Karl Greenblatt ${ }^{*}$ and Brave K. Nguyen
}

\begin{abstract}
Background: Acquired thrombophilia is a potential sequela of malignancy, chronic inflammation, and conditions characterized by severe protein deficiency (for example, nephrotic syndrome, protein-losing enteropathy). As such, venous thrombosis is often a feature, and occasionally a presenting sign, of systemic disease. Ménétrier's disease is a rare hyperplastic gastropathy that may lead to gastrointestinal protein loss and hypoalbuminemia. To date, reports of venous thrombosis associated with Ménétrier's disease are exceedingly scarce.
\end{abstract}

Case presentation: We report the case of a 40-year-old white man who presented with unprovoked deep venous thrombosis, pulmonary embolism, and renal vein thrombosis. Upon receiving therapeutic anticoagulation, he developed severe gastrointestinal bleeding, and endoscopic evaluation led to a diagnosis of Ménétrier's disease. A laboratory workup revealed deficiency of protein $\mathrm{C}$, protein $\mathrm{S}$, and antithrombin III, as well as markedly elevated levels of factor VIII. He was determined to have an acquired thrombophilia as a direct result of Ménétrier's disease.

Conclusions: This case describes an acquired thrombophilic state in a patient with Ménétrier's disease and profound hypoalbuminemia. Although this association is rarely described, we discuss the probable mechanisms leading to our patient's thrombosis. Specifically, we posit that his gastrointestinal protein loss led to a deficiency of several anticoagulant proteins and a compensatory elevation in factor VIII, as occurs in nephrotic syndrome and inflammatory bowel disease. Of note, this patient's recurrent venous thrombosis was the initial clinical sign of his gastrointestinal pathology.

Keywords: Thrombophilia, Hypercoagulable, Ménétrier's, Gastropathy, Hypoalbuminemia

\section{Background}

Thrombophilia refers to any condition that increases the risk of venous and/or arterial thrombosis, most commonly deep venous thrombosis (DVT) and pulmonary embolism (PE). Etiologies of thrombophilia may broadly be grouped into inherited conditions, including factor $\mathrm{V}$ Leiden and prothrombin gene mutation, and acquired conditions such as pregnancy, autoimmune disease, or malignancy. In patients with unprovoked DVT, especially those under age 50 , laboratory evaluation for possible thrombophilia is usually not recommended, as it is unlikely to change medical management [1]. However, unprovoked DVT is occasionally the first presentation of an underlying illness. For example, Trousseau syndrome refers to a well-described

\footnotetext{
* Correspondence: greenbhv@mail.uc.edu

University of Cincinnati College of Medicine, Cincinnati, OH 45219, USA
}

association between unprovoked DVT and gastric or pancreatic carcinoma [2]. Therefore, in some patients with recurrent thrombosis or thrombosis in an unusual location (for example, renal vein or portal vein), further workup for the source of hypercoagulability may be indicated.

Ménétrier's disease (MND) is a type of hyperplastic (or hypertrophic) gastropathy, first described by the French pathologist Pierre Ménétrier in 1888. To date, fewer than 1000 total cases have been reported. Its pathogenesis is driven by aberrant epidermal growth factor receptor (EGFR)-mediated signaling and overproduction of transforming growth factor alpha (TGFo) in the gastric mucosa. MND may be idiopathic but is strongly associated with Helicobacter pylori infection [3-5] and, in children, acute cytomegalovirus infection [6]. Typical presenting symptoms of MND are postprandial epigastric pain, early satiety, nausea/vomiting,

(c) The Author(s). 2019 Open Access This article is distributed under the terms of the Creative Commons Attribution 4.0 International License (http://creativecommons.org/licenses/by/4.0/), which permits unrestricted use, distribution, and reproduction in any medium, provided you give appropriate credit to the original author(s) and the source, provide a link to the Creative Commons license, and indicate if changes were made. The Creative Commons Public Domain Dedication waiver (http://creativecommons.org/publicdomain/zero/1.0/) applies to the data made available in this article, unless otherwise stated. 
and weight loss. The most frequently observed laboratory findings are hypoalbuminemia, hypochlorhydria, elevated serum gastrin, and iron deficiency anemia [7-12]. Imaging often reveals giant gastric folds, which have been said to resemble brain gyri [13]. Definitive diagnosis is made by biopsy; the most specific finding is foveolar hyperplasia without atypia or malignancy [14]. First-line treatment usually consists of a high-protein diet. Beyond this, the only satisfactory therapy has historically been total gastrectomy. More recently, several authors have reported regression of disease upon treatment with cetuximab, a monoclonal antibody against the EGFR receptor $[15,16]$. MND is believed to be a premalignant condition, although the precise risk of progression to gastric carcinoma remains uncertain [17].

Although gastric carcinoma itself has been associated with thrombophilia, published reports of unprovoked thrombosis associated with MND or other hyperplastic gastropathies are exceedingly scarce [18-20]. This report presents the case of a patient who presented with DVT, $\mathrm{PE}$, and renal vein thrombosis as the initial signs of MND. It will also discuss the mechanisms by which a protein-losing gastropathy such as MND could lead to a thrombophilic state.

\section{Case presentation}

A 40-year-old white man presented to an outside emergency department in June 2018 with sudden-onset right calf pain, swelling, and redness. He had a history of juvenile polyposis syndrome, for which he underwent a partial colectomy as a child, and alcohol use disorder (in remission). $\mathrm{He}$ received surveillance colonoscopies at recommended intervals due to his history of polyps, the most recent of which had been unremarkable. Upon presentation, a venous ultrasound revealed an acute, occluding thrombus of his right popliteal, tibial, and peroneal veins. There was no preceding history of trauma or immobilization. He was discharged on rivaroxaban $15 \mathrm{mg}$ twice daily and advised to follow-up with his primary care provider.

One week later, he presented again to an outside emergency department with a 3-day history of melena. An initial laboratory workup was significant for hemoglobin of 5.3 and mean corpuscular volume (MCV) of 55.7, for which he received 3 units of transfused red blood cells. Following stabilization and cessation of rivaroxaban, an abdominal computed tomography (CT) scan revealed a mass-like transmural thickening of the gastric antral and pyloric walls with tumor protrusion into the duodenal bulb. Also visualized were multifocal bilateral segmental and subsegmental pulmonary emboli, as well as a non-occlusive thrombus extending from his right renal vein into his suprarenal inferior vena cava (IVC). He underwent placement of an IVC filter. Subsequent upper endoscopy revealed diffusely irregular, raised gastric mucosa across the entire gastric body, with the appearance of a soft carpeted mass (Fig. 1). This finding was suggestive of malignancy. A biopsy specimen of the mass showed gastric mucosa with prominent foveolar hyperplasia, focal granulation tissue, ulceration, reactive glandular changes, and evidence of chronic active inflammation (Fig. 2). However, despite the suspicious gross appearance, there was no evidence of dysplasia or malignancy. Immunostaining was negative for Helicobacter pylori. Based on these findings, a probable diagnosis of MND was established. He was discharged on high-dose orally administered pantoprazole and scheduled for repeat upper endoscopy in 1 month.

Approximately 3 weeks later, he once again presented to an outside emergency department with the chief complaint of lumbar and suprapubic pain. An abdominal CT

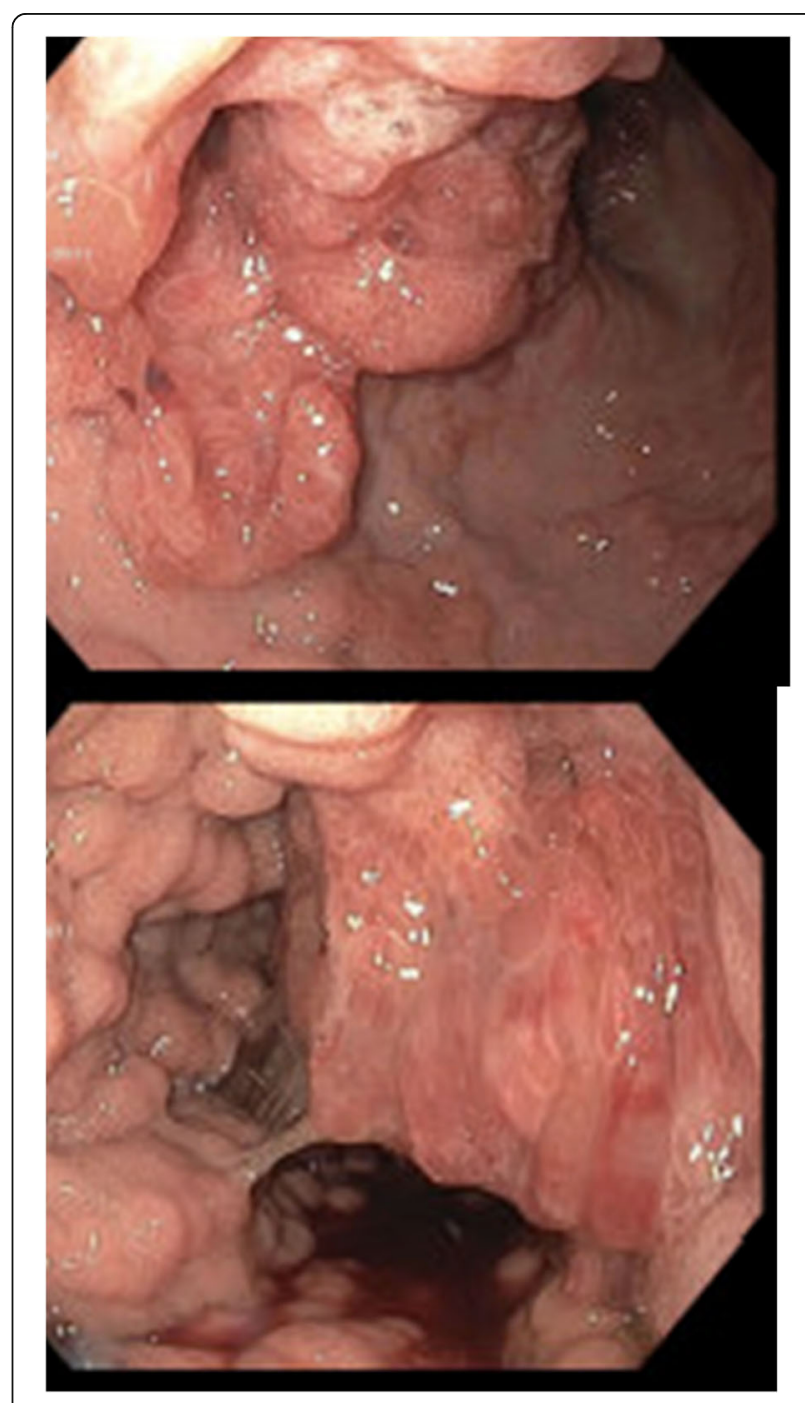

Fig. 1 Esophagogastroduodenoscopy images showing raised, soft, markedly irregular gastric mucosa, extending from the edge of the gastric fundus to the gastric antrum 


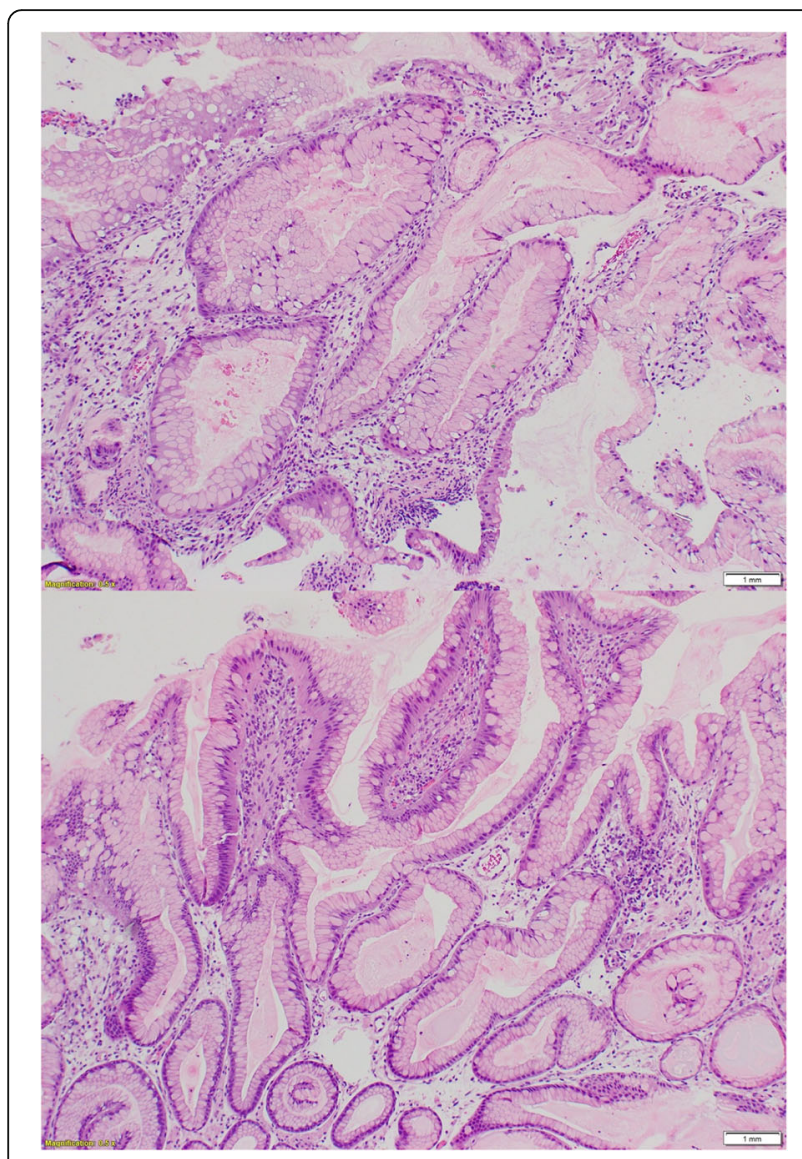

Fig. 2 Hematoxylin and eosin-stained slide of gastric biopsy specimen. Gastric mucosa with prominent foveolar hyperplasia, focal granulation tissue, ulceration, reactive glandular changes, and evidence of chronic active inflammation. No evidence of dysplasia or malignancy

scan again showed a non-occlusive thrombus of his right renal vein, which was now noted to extend slightly above the IVC filter. Also visualized were abdominal varices and cavernous transformation of his portal vein suggestive of previous portal vein thrombosis. Upon this finding, he was admitted to our institution as a direct transfer for symptomatic renal vein thrombosis. A low-dose heparin drip was initiated immediately. Following transfusion of 1 unit of packed red blood cells, his hemoglobin remained between 7.2 and 7.6, and he had no ongoing melena. A comprehensive metabolic panel was notable for serum albumin of 2.4. A serum gastrin level was also elevated to 244 (upper limit of normal, 150). During his admission, he developed painful bilateral lower extremity and scrotal edema, which was managed non-pharmacologically. An urgent repeat upper endoscopy was recommended, but he declined this procedure due to concerns about the risks of endoscopic mass removal. Further intervention was deferred to his primary gastroenterologist, although treatment with cetuximab was discussed as an eventual option. He was bridged to orally administered anticoagulation without incident and was discharged on apixaban $5 \mathrm{mg}$ twice daily for an indefinite duration. During a severalhour window when he was not anticoagulated, further laboratory evaluation of his hypercoagulability was performed; the results are shown in Table 1.

At 1-month follow-up with his primary care physician, he was tolerating apixaban well, with no further gastrointestinal (GI) bleeding. He was adhering to a high-protein diet with subjective and objective improvement in his edema. His hemoglobin improved to 8.8 and his albumin to 3.2. There were no other significant changes in his laboratory results. He continued to decline repeat endoscopy or mass removal. However, he expressed plans to seek care from an out-of-state oncologist and/or gastroenterologist with expertise in treating MND.

\section{Discussion}

There are several remarkable aspects to the above presentation. First, MND itself is quite rare, as discussed earlier. On endoscopy, the gross appearance of our patient's gastric lesion was initially most suggestive of malignancy; his hypoalbuminemia, hypercoagulability, hypochlorhydria, and GI bleeding could all have been consistent with gastric cancer as well as MND. The pretest probability for gastric cancer was especially high given his history of juvenile polyposis syndrome, which is known to increase the risk of malignancy throughout the GI tract [21]. In this case, the diagnosis of MND was not suspected until highly suggestive histopathologic findings were observed. Second, descriptions of unprovoked venous thrombosis associated with protein-losing gastropathy are exceedingly rare. This reflects the low incidence of MND as well as the highly atypical presentation illustrated in this case. Even more unusual, our patient presented with a lower extremity DVT as the initial sign of MND; GI bleeding only began after anticoagulation was initiated. Our patient had no preceding abdominal pain, nausea, early satiety, or weight loss, at least one of which is present in most reported cases of MND.

The single most unusual facet of this case is the development of an acquired thrombophilia associated with MND. Currently, there is no literature that clearly describes the pathogenesis of acquired thrombophilia in this particular setting. However, our patient did present with several laboratory abnormalities that could certainly explain his recurrent venous thrombosis. Such laboratory abnormalities are known to contribute to hypercoagulability in other, more common, systemic diseases. In particular, derangements of hemostasis that occur in other hypoalbuminemic states, such as nephrotic syndrome and inflammatory bowel disease (IBD), provide a foundation for understanding our patient's course. 
Table 1 Results of in-patient thrombophilia workup

\begin{tabular}{|c|c|c|c|}
\hline Test & Result & Normal range & Comment \\
\hline$\overline{\mathrm{DRWT}^{*}}$ & 41.6 seconds & $28.9-36.8$ seconds & $\begin{array}{l}\text { Suggests presence of "lupus-like" } \\
\text { coagulation inhibitor }\end{array}$ \\
\hline STACLOT-LA** delta & 14.7 seconds & $0.0-10.0$ seconds & $\begin{array}{l}\text { Suggests presence of "lupus-like" } \\
\text { coagulation inhibitor }\end{array}$ \\
\hline Anti-cardiolipin panel & Negative & Negative & \\
\hline Factor V Leiden assay & Negative & Negative & \\
\hline Protein C activity & $46 \%$ & $70-130 \%$ & Decreased \\
\hline Protein S, functional & $46 \%$ & $77-143 \%$ & Decreased \\
\hline Antithrombin III & $64 \%$ & $80-120 \%$ & Decreased \\
\hline Beta-2 glycoprotein IgG & $<9$ units & $0-20$ units & \\
\hline Factor $V$ assay & $97 \%$ & $65-150 \%$ & \\
\hline Factor VII assay & $113 \%$ & $60-150 \%$ & \\
\hline Factor VIII assay & $448 \%$ & $50-180 \%$ & Increased \\
\hline
\end{tabular}

*Dilute Russell viper venom time

**Hexagonal (II) phase phospholipid clotting assay

A brief review of normal hemostatic physiology will be pertinent to the discussion that follows. Normal hemostasis occurs in two stages, with primary hemostasis mediated by platelet adhesion and aggregation, and secondary hemostasis mediated by the clotting factors numbered II-XII. Endothelial injury leads to the exposure of tissue factor, which stimulates the proteolytic activation of factor II (thrombin). This stimulus is greatly amplified by the release of various platelet-derived mediators upon platelet aggregation. Once activated thrombin is generated, it directly activates factor V, factor VII (which in turn activates factor X), and factor XI (which in turn activates factor IX). The end result of the clotting cascade is the activation of fibrinogen to fibrin, which stabilizes the platelet plugs formed in primary hemostasis. The action of this cascade is delicately counterbalanced by endogenous anticoagulant proteins such as antithrombin III, protein C, and protein $\mathrm{S}$. When the zymogen forms of these proteins bind to activated clotting factors, they themselves are proteolytically activated and serve as a "check" upon secondary hemostasis. Given this physiology, it is clear that decreased anticoagulant protein activity and/or increased procoagulant protein activity (whether hereditary or acquired) may lead clinically to a hypercoagulable state. The most common hereditary thrombophilia is factor $\mathrm{V}$ Leiden, in which a mutated form of factor $\mathrm{V}$ is resistant to cleavage by protein $\mathrm{C}$; others include congenital antithrombin III deficiency and prothrombin gene mutation. These were considered less likely in our patient due to the timing and severity of his presentation, and factor V Leiden was specifically ruled out by laboratory testing. Causes of acquired thrombophilia include acquired antithrombin III deficiency, which has been described in a variety of systemic diseases and is known to increase the risk of venous thromboembolism (VTE)
[22, 23]. Acquired protein C deficiency [24] and protein $\mathrm{S}$ deficiency [25] in the setting of various conditions are also associated with increased thrombosis. Recent evidence has also demonstrated a predilection for VTE in patients with persistently elevated levels of factor VIII, which most commonly results from inflammation [26].

A systemic disease commonly associated with acquired thrombophilia is nephrotic syndrome, which is characterized by urinary protein loss exceeding 3 grams per 24 hours. Regardless of etiology, the various clinical manifestations of nephrotic syndrome result from damage to the glomerular filtration barrier. This leads to the selective loss of lower molecular size/weight proteins, most importantly albumin $(\sim 66.5 \mathrm{kDa})$, immunoglobulin $\mathrm{G}(\sim 50 \mathrm{kDa})$, and antithrombin III $(\sim 58 \mathrm{kDa})$. Extensive urinary loss of protein $\mathrm{S}(\sim 70 \mathrm{kDa})$ has also been described in the setting of nephrotic syndrome [27-29]. Conversely, proteins of higher molecular weights such as factor $\mathrm{V}(\sim 330 \mathrm{kDa})$ and factor VIII $(\sim 200 \mathrm{kDa})$, are generally not lost in the urine. An immediate consequence of this selective protein loss is an imbalance in the levels of endogenous procoagulant and anticoagulant proteins. However, there is also evidence of compensatory dysregulation of hepatic protein synthesis. Although incompletely understood, this dysregulation is believed to be triggered by albumin depletion, and it results in the synthesis of fibrinogen, factor V, and factor VIII out of proportion to urinary losses. This results in a more profound pro-thrombotic state and a greatly increased incidence of VTE including, but not limited to, renal vein thrombosis [30-32]. The hypoalbuminemia and intravascular volume depletion seen in nephrotic syndrome may also lead to relative platelet [33] and red blood cell [34] hyperaggregation, further increasing thrombotic risk.

Patients with IBD also have an elevated risk of VTE, up to four times that seen in the general population [35]. 
Similar to patients with nephrotic syndrome, decreased serum levels of albumin, immunoglobulins, and antithrombin III have been frequently observed in patients with IBD, as well as increased levels of factor V, factor VII, and factor VIII [36-40]. Protein C deficiency has also been reported in patients with IBD and thromboembolic disease [41]. IBD represents a systemic inflammatory state, which itself is a known risk factor for elevated factor VIII and VTE. However, there is no known association of antithrombin III, factor V, or factor VII levels with active inflammation. In addition, a significantly elevated risk of VTE has been reported even during disease remission [42]. It is therefore likely that other mechanisms are also involved in the thrombophilia of IBD. In particular, many patients with IBD have a clinically significant protein-losing enteropathy due to increased lymphatic and mucosal permeability [43-45]. As in nephrotic syndrome, hypercoagulability in protein-losing enteropathy is probably driven by the loss of antithrombin III and, to a lesser extent, protein $C$ and protein $S$ [46-48]. This mechanism is similar to that which occurs in patients with proteinlosing enteropathy secondary to Fontan-type cardiac procedures $[49,50]$.

Returning to our patient, we reiterate that he was found to have decreased antithrombin III, decreased protein $\mathrm{C}$ and $\mathrm{S}$, and increased factor VIII, in addition to profound hypoalbuminemia. These results provide evidence of an imbalance between procoagulant and anticoagulant proteins, a condition which clearly explains his acquired thrombophilia. Further, given the degree of hypoalbuminemia, it is reasonable to conclude that our patient's coagulation abnormalities developed via similar mechanisms as in nephrotic syndrome and IBD. In particular, we believe that the significant decrease in antithrombin III is a direct result of ongoing protein loss and is unlikely to be an artifact of active bleeding or systemic illness. Our patient also presented with a low level of serum protein $\mathrm{C}$ activity, a likely contributor to his hypercoagulability, yet protein $\mathrm{C}$ levels tend to be normal or even increased in nephrotic syndrome [51, 52]. This could be explained by slight differences in the selectivity of protein loss in different disease states-that is, if protein $\mathrm{C}$ may leak through damaged gastric mucosa more easily than a damaged glomerular filtration barrier. This is supported by the fact that protein $\mathrm{C}$ deficiency is observed in IBD more often than in nephrotic syndrome, as discussed above. Some degree of protein $\mathrm{C}$ deficiency can occur in the setting of severe inflammation, such as in patients with sepsis and multi-organ dysfunction [53]. However, given our patient's fairly stable general appearance, the degree of his protein $\mathrm{C}$ deficiency suggests an additional cause besides inflammation. We did not exclude a concomitant hereditary protein $\mathrm{C}$ deficiency with absolute certainty, although this is highly unlikely to present with multiple thromboses of sudden onset in middle age. Our patient's factor $\mathrm{V}$ level was within normal limits, although it is typically elevated in nephrotic syndrome and IBD. Because elevated factor $\mathrm{V}$ is a result of upregulated hepatic protein synthesis, which takes time to occur, studies obtained later in the disease course may have revealed increased factor V. However, our patient had experienced a sufficient duration of protein loss to present with a serum albumin of 2.4. It is possible that GI protein loss in MND does not affect hepatic protein synthesis in the same way as nephrotic syndrome, although this hypothesis would require further investigation. In contrast, levels of factor VIII, which is an acute-phase inflammatory reactant, could be expected to rise in a hospitalized patient even in the absence of hepatic protein over-synthesis. This rise was in fact observed in our patient.

Two important clinical questions were difficult to answer conclusively based on our patient's course. First, the connection between this patient's MND and his history of childhood juvenile polyposis syndrome is uncertain. Juvenile polyposis syndrome is an autosomal dominant disorder characterized by multiple hamartomatous polyps, nearly always involving the colon. However, $14 \%$ of patients with this syndrome also have gastric involvement [54]. An entity known as "massive gastric juvenile-type polyposis" has also been described in patients with and without known juvenile polyposis syndrome [55]. In addition, some reports have described an association between juvenile polyposis syndrome and MND and hypothesized that they may be manifestations of the same disease process $[56,57]$. Our patient's diagnosis of juvenile polyposis syndrome was remote, so we could not verify whether he was evaluated for gastric polyps at the time of colectomy or whether he ever received surveillance upper endoscopy. It is possible that further immunohistochemical or genetic testing would change the diagnosis from MND to juvenile or "juvenile-type" gastric polyposis. However, the resulting protein-losing gastropathy and hematologic sequelae would almost certainly be the same, regardless of diagnostic nomenclature.

Second, and more importantly for the purposes of this report, we could not easily explain the positive result for lupus-like anticoagulants. This represents another potential contributor to our patient's hypercoagulable state, as the risk of unprovoked thrombosis in patients with antiphospholipid antibody syndrome is well characterized, with or without concomitant systemic lupus erythematosus (SLE). Antiphospholipid antibody syndrome has never been documented in association with MND, and our patient had no other manifestations of SLE. To the best of our knowledge, there are no other systemic autoimmune diseases that commonly present with protein-losing gastropathy. Elinav et al. described 
one patient whose initial presentation of SLE was the development of hyperplastic gastropathy [58]. While it would be reasonable to monitor our patient for signs of SLE in the future, this would remain a very unlikely development. False positive antiphospholipid antibody results have been described in patients who have received rivaroxaban within 24 hours and possibly up to several days [59-61]. To the best of our knowledge, however, our patient last received rivaroxaban several weeks prior to the antiphospholipid assay, so we consider this an unlikely explanation. Interestingly, the presence of low serum fibrinogen has been noted to interfere with the dilute Russell viper venom assay for lupus anticoagulant [62]. We did not measure our patient's serum fibrinogen, but it was probably low in the presence of acute thrombosis. Ultimately, therefore, we believe that laboratory artifact was the most likely explanation for the positive lupus-like anticoagulant.

\section{Conclusions}

In summary, we present the case of a 40-year-old man who developed acquired thrombophilia secondary to a protein-losing gastropathy. This case highlights an extremely rare cause of thrombophilia, made more notable by the fact that unprovoked venous thrombosis was the initial disease manifestation. We underscore the importance of maintaining a broad differential diagnosis when evaluating a patient with acquired hypercoagulability. Our patient's case was also complicated by the development of GI bleeding when therapeutic anticoagulation was initiated. His simultaneous bleeding and hypercoagulability presented a distinct clinical challenge, which ultimately necessitated in-patient observation and unfractionated heparin therapy.

The strengths of this case report include its novelty; we describe a rare disease process involving the GI system, with even more unusual hematologic manifestations. The workup of our patient was quite thorough, as it involved multiple hospital admissions and subspecialty evaluations. In addition, coagulation studies were drawn after all anticoagulants had been held for a sufficient duration, minimizing the likelihood of medication-induced abnormalities. The limitations of this case report include sub-optimal followup, largely because our patient refused repeat endoscopy and sought further care out-of-state. There are also several causes of thrombophilia that were not assessed in this patient-for example, increased activity of prothrombin or homocysteine. At the discretion of the treating clinicians, these tests were withheld because they were felt to be low yield and unlikely to influence management.

\section{Acknowledgements}

The authors wish to thank Benjamin Hinrichs, MD (University of Cincinnati College of Medicine, Department of Pathology and Laboratory Medicine) for his contribution to this report.
Funding

Not applicable.

\section{Availability of data and materials \\ Not applicable.}

\section{Authors' contributions}

Both HKG and BKN examined the patient clinically, analyzed laboratory and histopathology data, and discussed the case with the relevant consulting physicians. HKG was the major contributor in drafting the manuscript. BKN provided a supervising and editorial role. Both authors read and approved the final manuscript.

\section{Ethics approval and consent to participate}

Not applicable.

\section{Consent for publication}

Written informed consent was obtained from the patient for publication of this case report and any accompanying images. A copy of the written consent is available for review by the Editor-in-Chief of this journal.

\section{Competing interests}

The authors declare that they have no competing interests.

\section{Publisher's Note}

Springer Nature remains neutral with regard to jurisdictional claims in published maps and institutional affiliations.

Received: 29 August 2018 Accepted: 12 December 2018

Published online: 17 January 2019

\section{References}

1. Stevens SM, Woller SC, Bauer KA, et al. Guidance for the evaluation and treatment of hereditary and acquired thrombophilia. J Thromb Thrombolysis. 2016:41(1):154-64.

2. Ikushima S, Ono R, Fukuda K, Sakayori M, Awano N, Kondo K. Trousseau's syndrome: cancer-associated thrombosis. Jpn J Clin Oncol. 2016;46(3):204-8.

3. Fretzayas A, Moustaki M, Alexopoulou E, Nicolaidou P. Menetrier's disease associated with Helicobacter pylori: three cases with sonographic findings and a literature review. Ann Trop Paediatr. 2011;31(2):141-7.

4. Kuzuya T, Kumada T, Kiriyama S, et al. Contrast-enhanced ultrasonographic assessment of the response of Menetrier disease to Helicobacter pylori eradication therapy. J Ultrasound Med. 2006;25(8):1099-103.

5. Ding Q, Lu P, Ding S, et al. Menetrier disease manifested by polyposis and involved in both the small bowel and entire colon: A Case Report. Medicine (Baltimore). 2016;95(36):e4685.

6. Megged O, Schlesinger Y. Cytomegalovirus-associated protein-losing gastropathy in childhood. Eur J Pediatr. 2008;167(11):1217-20.

7. Lambrecht NW. Menetrier's disease of the stomach: a clinical challenge. Curr Gastroenterol Rep. 2011;13(6):513-7.

8. Stamm B. Localized hyperplastic gastropathy of the mucous cell- and mixed cell-type (localized Menetrier's disease): a report of 11 patients. Am J Surg Pathol. 1997;21(11):1334-42.

9. Searcy RM, Malagelada JR. Menetrier's disease and idiopathic hypertrophic gastropathy. Ann Intern Med. 1984;100(4):565-70.

10. Bancila I, Popescu I, Herlea V, Becheanu G, Dumbrava M, Gheorghe C. Menetrier's disease: a rare entity which mimicks gastric cancer. J Gastrointestin Liver Dis. 2016;25(2):137.

11. Famularo G, Sajeva MR, Gasbarrone L. Beyond gastritis and before cancer: the strange case of Menetrier's disease. Intern Emerg Med. 2011;6(4):369-71.

12. Rich A, Toro TZ, Tanksley J, et al. Distinguishing Menetrier's disease from its mimics. Gut. 2010;59(12):1617-24.

13. Akita C, Saikawa Y. Gastric Gyri - Pediatric Menetrier's Disease. N Engl J Med. 2017;376(8):774

14. Wolfsen HC, Carpenter HA, Talley NJ. Menetrier's disease: a form of hypertrophic gastropathy or gastritis? Gastroenterology. 1993;104(5):1310-9.

15. Fiske WH, Tanksley J, Nam KT, et al. Efficacy of cetuximab in the treatment of Menetrier's disease. Sci Transl Med. 2009;1(8):8ra18.

16. Settle SH, Washington K, Lind C, et al. Chronic treatment of Menetrier's disease with Erbitux: clinical efficacy and insight into pathophysiology. Clin Gastroenterol Hepatol. 2005;3(7):654-9. 
17. Ramia JM, Sancho E, Lozano O, Santos JM, Dominguez F. Menetrier's disease and gastric cancer. Cir Esp. 2007;81(3):153-4.

18. Gerada J, Borg E, DeGaetano J, Pocock J. Giant gastric folds in a patient with hypoalbuminaemia. BMJ Case Rep. 2013;2013 https://doi.org/10.1136/ bcr-2012-008284.

19. McDermott VG, Connolly CE, Finnegan P, O'Gorman T. Menetrier's disease presenting with deep venous thrombosis, iron deficiency anaemia and early evolution to atrophic gastritis. Ir J Med Sci. 1986;155(2):53-4.

20. Gower-Rousseau C, Guillemot F, Chiche A, et al. Thromboembolism as the first symptom of Menetrier's disease. Am J Gastroenterol. 1992:87(5):681-2.

21. Calva D, Howe J. Juvenile Polyposis. In: Riegert-Johnson DL, Boardman LA, Hefferon T, Roberts M, editors. Cancer Syndromes. Bethesda: National Center for Biotechnology Information; 2009.

22. Buller HR, ten Cate JW. Acquired antithrombin III deficiency: laboratory diagnosis, incidence, clinical implications, and treatment with antithrombin III concentrate. Am J Med. 1989;87(3B):44S-8S,

23. Ornaghi S, Barnhart KT, Frieling J, Streisand J, Paidas MJ. Clinical syndromes associated with acquired antithrombin deficiency via microvascular leakage and the related risk of thrombosis. Thromb Res. 2014;133(6):972-84.

24. Kottke-Marchant K, Comp P. Laboratory issues in diagnosing abnormalities of protein C, thrombomodulin, and endothelial cell protein C receptor. Arch Pathol Lab Med. 2002;126(11):1337-48.

25. Kemkes-Matthes B. Acquired protein S deficiency. Clin Investig. 1992;70(6): 529-34.

26. Jenkins PV, Rawley O, Smith OP, O'Donnell JS. Elevated factor VIII levels and risk of venous thrombosis. Br J Haematol. 2012;157(6):653-63.

27. Vigano-D'Angelo S, D'Angelo A, Kaufman CE Jr, Sholer C, Esmon CT, Comp PC. Protein S deficiency occurs in the nephrotic syndrome. Ann Intern Med. 1987;107(1):42-7.

28. Song KS, Won DI, Lee AN, Kim CH, Kim JS. A case of nephrotic syndrome associated with protein $\mathrm{S}$ deficiency and cerebral thrombosis. J Korean Med Sci. 1994;9(4):347-50

29. Hanevold CD, Lazarchick J, Constantin MA, Hiott KL, Orak JK. Acquired free protein $\mathrm{S}$ deficiency in children with steroid resistant nephrosis. Ann Clin Lab Sci. 1996;26(3):279-82.

30. Singhal R, Brimble KS. Thromboembolic complications in the nephrotic syndrome: pathophysiology and clinical management. Thromb Res. 2006; 118(3):397-407.

31. Kerlin BA, Ayoob R, Smoyer WE. Epidemiology and pathophysiology of nephrotic syndrome-associated thromboembolic disease. Clin J Am Soc Nephrol. 2012;7(3):513-20.

32. Barbano B, Gigante A, Amoroso A, Cianci R. Thrombosis in nephrotic syndrome. Semin Thromb Hemost. 2013;39(5):469-76.

33. Tkaczyk M, Baj Z. Surface markers of platelet function in idiopathic nephrotic syndrome in children. Pediatr Nephrol. 2002;17(8):673. -677, 2002

34. Bohler T, Linderkamp O, Leo A, Wingen AM, Scharer K. Increased aggregation with normal surface charge and deformability of red blood cells in children with nephrotic syndrome. Clin Nephrol. 1992;38(3):119-24

35. Magro F, Soares JB, Fernandes D. Venous thrombosis and prothrombotic factors in inflammatory bowel disease. World J Gastroenterol. 2014;20(17): 4857-72.

36. Rai T, Wu X, Shen B. Frequency and risk factors of low immunoglobulin levels in patients with inflammatory bowel disease. Gastroenterol Rep (Oxf). 2015;3(2):115-21.

37. Vanis N, Mehmedovic A, Mesihovic R, Saray A. Anaemia and inflammatory bowel disease. Pril (Makedon Akad Nauk Umet Odd Med Nauki). 2013;34(2):35-42.

38. Zezos P, Kouklakis G, Saibil F. Inflammatory bowel disease and thromboembolism. World J Gastroenterol. 2014;20(38):13863-78

39. Owczarek D, Cibor D, Glowacki MK, Rodacki T, Mach T. Inflammatory bowel disease: epidemiology, pathology and risk factors for hypercoagulability. World J Gastroenterol. 2014;20(1):53-63.

40. Hudson M, Chitolie A, Hutton RA, Smith MS, Pounder RE, Wakefield AJ Thrombotic vascular risk factors in inflammatory bowel disease. Gut. 1996; 38(5):733-7.

41. Korsten S, Reis HE. Acquired protein C deficiency in ulcerative colitis. The cause of thromboembolic complications. Dtsch Med Wochenschr. 1992; 117(11):419-24.

42. Nguyen $\mathrm{GC}$, Bernstein $\mathrm{CN}$, Bitton $\mathrm{A}$, et al. Consensus statements on the risk, prevention, and treatment of venous thromboembolism in inflammatory bowel disease: Canadian Association of Gastroenterology. Gastroenterology. 2014;146(3):835-48. e836
43. Braamskamp MJ, Dolman KM, Tabbers MM. Clinical practice. Protein-losing enteropathy in children. Eur J Pediatr. 2010;169(10):1179-85.

44. Acciuffi S, Ghosh S, Ferguson A. Strengths and limitations of the Crohn's disease activity index, revealed by an objective gut lavage test of gastrointestinal protein loss. Aliment Pharmacol Ther. 1996;10(3):321-6.

45. Hebuterne X, Filippi J, Al-Jaouni R, Schneider S. Nutritional consequences and nutrition therapy in Crohn's disease. Gastroenterol Clin Biol. 2009; 33(Suppl 3):S235-44.

46. Kawaguchi Y, Mine T, Kawana I, Umemura S. Protein-losing enteropathy, deep venous thrombosis and pulmonary embolism in a patient with generalized inflammatory polyposis in remission stage of ulcerative colitis. Clin J Gastroenterol. 2009;2(3):156-60

47. Subijay S, Shikha G, Yogesh B, Varun G, Sumeet K, Pradeep V. An unusual cause of macular infarction: protein-losing enteropathy. Int Ophthalmol. 2012:32(6):519-21.

48. Goodwin LV, Goggs R, Chan DL, Allenspach K. Hypercoagulability in dogs with protein-losing enteropathy. J Vet Intern Med. 2011;25(2):273-7.

49. Cromme-Dijkhuis AH, Henkens CM, Bijleveld CM, Hillege HL, Bom VJ, van der Meer J. Coagulation factor abnormalities as possible thrombotic risk factors after Fontan operations. Lancet. 1990;336(8723):1087-90.

50. Jahangiri M, Shore D, Kakkar V, Lincoln C, Shinebourne E. Coagulation factor abnormalities after the Fontan procedure and its modifications. J Thorac Cardiovasc Surg. 1997;113(6):983-92.

51. Soff GA, Sica DA, Marlar RA, Evans HJ, Qureshi GD. Protein C levels in nephrotic syndrome: use of a new enzyme-linked immunoadsorbent assay for protein C antigen. Am J Hematol. 1986;22(1):43-9.

52. Mannucci PM, Valsecchi C, Bottasso B, D'Angelo A, Casati S, Ponticelli C. High plasma levels of protein $C$ activity and antigen in the nephrotic syndrome. Thromb Haemost. 1986;55(1):31-3.

53. Shaw AD, Vail GM, Haney DJ, Xie J, Williams MD. Severe protein C deficiency is associated with organ dysfunction in patients with severe sepsis. J Crit Care. 2011;26(6):539-45.

54. Soer E, de Vos Tot Nederveen Cappel WH, Ligtenberg MJ, et al. Massive gastric polyposis associated with a germline SMAD4 gene mutation. Familial Cancer. 2015;14(4):569-73.

55. Gonzalez RS, Adsay V, Graham RP, et al. Massive gastric juvenile-type polyposis: a clinicopathological analysis of 22 cases. Histopathology. 2017; 70(6):918-28.

56. Piepoli A, Mazzoccoli G, Panza A, et al. A unifying working hypothesis for juvenile polyposis syndrome and Menetrier's disease: specific localization or concomitant occurrence of a separate entity? Dig Liver Dis. 2012;44(11):952-6.

57. Burmester JK, Bell LN, Cross D, Meyer P, Yale SH. A SMAD4 mutation indicative of juvenile polyposis syndrome in a family previously diagnosed with Menetrier's disease. Dig Liver Dis. 2016;48(10):1255-9.

58. Elinav E, Korem M, Ofran $Y$, et al. Hyperplastic gastropathy as a presenting manifestation of systemic lupus erythematosus. Lupus. 2004;13(1):60-3.

59. Goralczyk T, Iwaniec T, Wypasek E, Undas A. False-positive lupus anticoagulant in patients receiving rivaroxaban: $24 \mathrm{~h}$ since the last dose are needed to exclude antiphospholipid syndrome. Blood Coagul Fibrinolysis. 2015;26(4):473-5.

60. Martinuzzo ME, Forastiero R, Duboscq C, et al. False-positive lupus anticoagulant results by DRWT in the presence of rivaroxaban even at low plasma concentrations. Int J Lab Hematol. 2018. Epub ahead of print; https://doi.org/10.1111/ijJh.12865.

61. Murer LM, Pirruccello SJ, Koepsell SA. Rivaroxaban Therapy, False-Positive Lupus Anticoagulant Screening Results, and Confirmatory Assay Results. Lab Med. 2016;47(4):275-8.

62. Moore GW. Current controversies in lupus anticoagulant detection. Antibodies. 2016;5(4):22. 